\title{
Horkheimer e a análise da sociedade reificada nos aforismos de Dämmerung ${ }^{1}$
}

\section{Horkheimer and the analysis of the reified society in the aphorisms of Dämmerung}

\author{
Simone Bernardete Fernandes \\ Graduanda, Departamento de Filosofia, Universidade de São Paulo - USP, São Paulo, SP, Brasil.
}

Resumo: Este artigo propõe uma análise dos aforismos de Dämmerung, escritos por Horkheimer entre 1926 e 1931, tendo em vista o desenvolvimento de sua filosofia ao longo da década de 1930. Tal investigação busca explicitar, nos aforismos, a presença de temas e influências teóricas que seriam encontrados em textos posteriores e comentar a importância do conceito de reificação e sua relação com os temas abordados pelo autor.

Palavras-chave: Teoria Crítica, emancipação, reificação, marxismo, moral, compaixão.

Abstract: This article proposes an analysis of the aphorisms of Dämmerung, which were written by Horkheimer between 1926 and 1931, considering the posterior development of this philosophy in the 1930s. Such an investigation aims to clarify, in the aphorisms, the presence of themes and theoretical influences that can be found in posterior works and to comment the importance of the concept of reification and its relation with the themes mentioned by the author.

Keywords: Critical Theory, emancipation, reification, marxism, moral, compassion.

\footnotetext{
${ }^{1}$ Uma versão anterior deste texto foi apresentada no VI Encontro de pesquisa na graduação em filosofia da UFSCar, campus São Carlos, em novembro de 2014
} 
Os aforismos publicados sob o título de Dämmerung ${ }^{2}$ foram elaborados por Horkheimer entre 1926 e 1931, momento que antecede a publicação de seus textos mais difundidos atualmente. A opção usual pelo foco no estudo dos escritos dos anos 1930 se relaciona ao fato de ser este o período inicial de sua atuação como diretor do Instituto de pesquisa social, ${ }^{3}$ colocando em prática o projeto do materialismo interdisciplinar e elaborando diversos ensaios para a revista do Instituto, e por ser o período de formulação da Teoria Crítica (em "Teoria tradicional e Teoria Crítica", de 1937). Já o interesse por seu trabalho dos anos 1940 está vinculado à Dialética do Esclarecimento, que representa uma ruptura considerável em relação aos escritos anteriores e um diagnóstico de época em que as possibilidades de emancipação parecem bloqueadas ${ }^{4}$. Mesmo considerando os textos destas duas décadas centrais na produção do autor, este artigo aborda os aforismos escritos entre 1926 e 1931, pois sua análise pode trazer luz a concepções que seriam desenvolvidas posteriormente ${ }^{5}$. Essa aproximação se revela significativa, sobretudo em relação aos anos 1930, pois, como atesta Abromeit, os escritos das décadas de 1920 e 1930 são mais próximos entre si do que os textos dos anos 1940 e tudo que os antecedeu (ABROMEIT, 2011, p. 227).

Assim, pretende-se analisar os aforismos de Dämmerung levando em conta sua afinidade com os escritos dos anos 1930, de modo a verificar que caminhos para a formulação da Teoria Crítica já estariam abertos então, mesmo que de forma incipiente, e quais as influências teóricas mais relevantes neste período. Para tal aproximação, com relação aos anos 1930, há referências a "A presente situação da filosofia social e as tarefas de um instituto de pesquisas sociais" $(1931)^{6}$ e "Teoria tradicional e Teoria Crítica" (1937), por representarem momentos chave do pensamento do autor. Além disso, este trabalho aborda as concepções de Horkheimer a respeito da moral e da compaixão, temas que atravessam sua obra desde os aforismos de Dämmerung, sendo referidos no ensaio "Materialismo e moral" (1933)

Para uma breve caracterização da produção do autor nos anos 1930, interessa esclarecer dois termos acima apresentados. O materialismo interdisciplinar, que se concretizou no programa de pesquisas do Instituto no começo dos anos 1930, está vinculado à proposta de reformulação do papel da filosofia social, orientando pesquisas empíricas de diversas áreas do conhecimento (como psicologia, sociologia, história, economia) e ao mesmo tempo recebendo influência destas. Com esta mútua influência, pretendia-se conservar a intenção de abarcar o universal mesmo em um contexto de especialização das áreas do conhecimento, pois os problemas filosóficos poderiam ser inseridos dialeticamente no processo empírico-científico. Desta maneira, seria possível evitar a concepção positivista

\footnotetext{
${ }^{2}$ Os referidos aforismos foram publicados inicialmente sob o pseudônimo de Heinrich Regius, em 1934. O título da obra pode caracterizar tanto "aurora" como "crepúsculo" e não foi aqui traduzido de modo a não perder o duplo sentido.

${ }^{3}$ O Instituto de pesquisa social iniciou suas atividades em 1923, sob diretoria de Carl Grünberg, e o ponto de união entre os pesquisadores associados foi desde o início a teoria marxista, tendo o Instituto realizado seminários de estudo, elaborado uma compilação da história do movimento operário e do socialismo e contribuído com o Institut Marx-Engels de Moscou. Com Horkheimer em sua diretoria, esta orientação marxista seria mantida, mas com alterações no plano de trabalho do Instituto, conforme exposto a seguir (JAY, 2008, p. 39-83).

${ }^{4}$ A Dialética do Esclarecimento foi escrita ao longo dos anos 1940, em parceria com Adorno, e publicada em 1947. Sobre esta mudança no diagnóstico de época (NOBRE, 2008, p. 46-49.

${ }^{5}$ De modo geral, estes aforismos são pouco citados na literatura de comentário, porém receberam maior atenção no trabalho de John Abromeit, Max Horkheimer and the foundations of the Frankfurt School. Ao realizar um estudo detido e consistente do desenvolvimento intelectual de Horkheimer, Abromeit reservou espaço considerável a estes aforismos, por perceber neles, ainda que de modo incipiente, elementos que seriam desenvolvidos pelo autor nos anos 1930 e que se estão ligados à formulação da Teoria Crítica (ABROMEIT, 2011, p. 156-180).

${ }^{6}$ Conferência de posse de Horkheimer na diretoria do Instituto de pesquisa social, em janeiro de 1931.
}

${ }^{7}$ Ainda que este estudo se circunscreva aos anos 1930, vale comentar que estas questões também estão presentes no Excurso "Juliette ou esclarecimento e moral", de Dialética do esclarecimento, porém sob outra perspectiva e relacionadas a outro diagnóstico de época (ADORNO; HORKHEIMER, 2006, p. 71-98). 
de conhecimento, que tratava os fatos como confirmação ou falsificação da teoria, e também a armadilha, presente no marxismo ocidental, de não levar em conta os fatos empíricos que contradissessem a teoria (JAY, 1984, p. 200-202; Idem, 2008, p. 90). Quanto à Teoria Crítica, sua formulação também se dá sob o pano de fundo da especialização das áreas de conhecimento, apregoando a necessidade da autoconsciência de sua limitação. Horkheimer apresenta a Teoria Crítica como constituindo o autoconhecimento do homem, um movimento já existente, baseado nas análises de Marx, e que busca constante atualização de diagnóstico de época com vistas ao estabelecimento de um estado racional na sociedade, ou seja, uma teoria não apenas descritiva, mas voltada à transformação social. ${ }^{8}$

\section{Panorama geral de Dämmerung}

De modo a identificar as aproximações entre os escritos de 1926-1931 e alguns temas desenvolvidos adiante na década de 1930, passaremos à análise dos aforismos de Dämmerung. No prefácio, o autor já alude a alguns tópicos a serem abordados: “[...] os conceitos de metafísica, caráter, moral, personalidade e o valor do homem na forma que possuem neste período do capitalismo [...]" (HORKHEIMER, 1986, p. 18-19). Mas entre os aforismos há uma diversidade maior de motivos. Há interesse em temas relacionados às possibilidades revolucionárias, como a organização política dos trabalhadores, as atitudes dos revolucionários, dos partidos e sindicatos (Ibidem, p. 27, 49, 55, 85, 136, 156, 165). Horkheimer critica alguns marxistas de seu tempo pela exaltação do trabalho como atividade essencial do homem, o que qualificava como ideologia ascética, e pela ideia de que o socialismo decorreria naturalmente das leis econômicas ou da história, assim como questionava o papel dos partidos em sua realização (Ibidem, p. 50, 120, 127) . O autor também versa sobre as ideologias e sanções que ameaçavam quem ousasse se colocar contra a ordem vigente (Ibidem, p. 19,39, 139). A ciência de seu tempo é criticada pela suposição da neutralidade do sujeito do conhecimento e pelo seu academicismo (Ibidem, p. 24, 48,74). A religião e os ideais iluministas são problematizados, não como falsa consciência, mas tendo, em determinado momento, seu núcleo de verdade colocado na intenção contra o sofrimento humano (Ibidem, p. 34, 82, 91, 94; ABROMEIT, 2011, p. 166, 172; JAY, 2008, p. 99-100). Sobretudo, de modo destacado, questões referentes à metafísica (HORKHEIMER, 1986, p. 63, 92) ${ }^{10}$, à personalidade, à moral e ao valor do homem (Ibidem, p. 25, 29, 33, 46, 61, 64, 76, 97, 119, 123, 126, 145), mencionadas no prefácio, encontram expressão em boa parte dos aforismos.

\footnotetext{
${ }^{8}$ A menção a estes textos dos anos 1930 não considera, entretanto, que haja homogeneidade no diagnóstico de época entre eles, pois em 1937 este já começara a se alterar. Sobre esta mudança de diagnóstico, três elementos são citados por Nobre: a influência das análises econômicas de Pollock referentes à transição ao capitalismo monopolista e caracterizado por intervenções estatais na economia; a diferenciação social dentro do proletariado, que dificultava sua organização para a ação; e, por fim, a ascensão do nazismo e do fascismo, com a consequente ampliação das formas de controle social por estes poderes autoritários (NOBRE, 2008, p. 40-41).

${ }^{9}$ Como nota Wiggershaus, Horkheimer permanece, nos anos 1930, recusando uma lógica imanente na história que levasse ao colapso econômico e à revolução e argumentando contra aqueles que apoiassem tal lógica (WIGGERSHAUS, 2002, p. 79-82).

${ }^{10}$ Devido aos limites deste trabalho, o tema da metafísica não será amplamente explorado. Ainda seja recorrente em Dämmerung e na obra posterior de Horkheimer, como atesta Habermas, a sua concepção sobre o tema pouco se altera na década de 1930, havendo apenas nuances conforme os "tipos" de metafísicas abordadas. Observe-se que, em Dämmerung, a metafísica é criticada por amenizar o descontentamento dos homens com a ordem vigente: "a essência das coisas está articulada de tal maneira que se pode investigar e viver em sua contemplação, sem cair na indignação contra o sistema social vigente" (HORKHEIMER, 1986 p. 63). Em escritos posteriores, como Origens da filosofia burguesa da história (1931), "Hegel e o problema da metafísica" (1932), "Materialismo e metafísica" (1933), "Sobre a metafísica do tempo de Bergson" (1934), "Da discussão do racionalismo na filosofia contemporânea" (1934), Horkheimer procura elucidar em que sentido uma visão metafísica de mundo pode ser nociva para as possibilidades revolucionárias, ao favorecer a justificação do status quo. De modo geral, como observa Brunkhorst, o argumento central do autor contra a metafísica é que esta se coloca a serviço da transfiguração (HABERMAS, 2007, p. 274; BRUNKHORST, 1993, p. 70; STIRK, 1992, p. 37-61).
} 
Face à diversidade de temas e ao estilo fragmentar de sua apresentação, foi obtida uma chave de leitura através da interpretação de Abromeit (2011, p. 158-159, grifo nosso), que afirma:

O central, se não o único, problema que Horkheimer aborda em Dämmerung são as várias formas como a dinâmica historicamente única da sociedade capitalista se reproduz através do conhecimento e da ignorância, da ação e inação, de comportamentos, atitudes e sentimentos de indivíduos concretos. [...] [Horkheimer] descreve e analisa, em outras palavras, as manifestações concretas de relações sociais reificadas que se tornaram segunda natureza no capitalismo moderno.

Partindo destas considerações, os aforismos serão analisados como um diagnóstico da sociedade reificada e seus desdobramentos concretos. Esta chave de leitura os aproxima das concepções de Lukács em História e consciência de classe (1923), pela via do conceito de reificação, e também do trabalho do próprio autor nos anos 1930, inspirado pelo materialismo interdisciplinar, se entendido como continuidade deste interesse na compreensão dos indivíduos concretos e como tentativa de superar a unilateralidade das ciências. A leitura de Abromeit abre espaço a esta compreensão, por considerar que os aforismos estariam "[...] informados por uma incipiente teoria da sociedade baseada em algumas das tendências mais avançadas da pesquisa sociológica e psicológica de seu tempo [...]", (Ibidem, p. 157) já apontando para o interesse de Horkheimer em trabalhar em conjunto com outras áreas do conhecimento. A seguir, alguns aforismos serão apresentados de modo a explicitar a aplicação destas diretrizes aos temas abordados pelo autor. Em paralelo, serão identificadas algumas de suas influências teóricas.

Importa ressaltar que a análise aqui proposta não pretende esgotar a riqueza de temas dos aforismos, mas trazer à discussão a gênese de algumas questões presentes na produção posterior do autor. Também se deve considerar o fato de que, em alguns casos, podem ser encontradas perspectivas distintas sobre os mesmos temas. O próprio autor admite estas contradições, relacionadas ao fato de eles terem sido escritos em um período de seis anos e de modo fragmentar ${ }^{11}$. Exemplo disto é a posição de Horkheimer quando à viabilidade de uma revolução proletária, que aparece em alguns aforismos como uma possibilidade no horizonte, mas, em "A impotência da classe trabalhadora alemã", (HORKHEIMER, 1986, p. 85) já bloqueada devido às divisões internas dentro do proletariado. No prefácio, fazendo referência às vitórias obtidas pelo nacional-socialismo desde sua publicação, Horkheimer considera que algumas destas ideias "se referem a um mundo já superado hoje" (Ibidem, p. 17).

\section{Sobre a presença do conceito de reificação no pensamento de Horkheimer}

O termo reificação remete a uma leitura da obra tardia de Marx por Lukács ${ }^{12}$, ancorada na análise do caráter fetichista da mercadoria, mas também inspirada pela ideia de um processo de racionalização e autonomização das esferas de valor (ou sistemas parciais, como nomeia Lukács), proveniente do pensamento de Max Weber. Assim escreveu Marx sobre os desdobramentos da análise do fetichismo da mercadoria:

Fórmulas que não deixam lugar a dúvidas de que pertencem a uma formação social em que o processo de produção domina o homem e ainda não o homem o processo de produção

\footnotetext{
${ }^{11}$ Isso pode ser encontrado no prefácio à publicação dos aforismos, de 1933 (HORKHEIMER, 1986, p. 17).

${ }^{12} \mathrm{~A}$ influência de Lukács no ambiente intelectual de surgimento do Instituto de pesquisa social desde seu início é atestada por Martin Jay em Marxism and Totality (JAY, 1984 p. 197).
} 
são consideradas por sua consciência burguesa uma necessidade natural tão evidente como o próprio trabalho produtivo. (MARX, 1985, p. 7677, grifo nosso).

A união de concepções marxistas e weberianas é expressa na seguinte passagem de História e consciência de classe, acerca da estrutura da forma mercadoria:

[...] uma relação entre pessoas tomar o caráter de uma coisa, uma 'objetividade fantasmagórica' que, em sua legalidade própria, rigorosa, aparentemente racional e inteiramente fechada, oculta todo traço de sua essência fundamental: a relação entre os homens [...]. (LUKÁCS, 2012, p. 194),

passagem na qual há indícios também da racionalização e da autonomização das esferas de valor. Em sua elaboração do conceito de reificação, Lukács destaca a imediatez, a naturalização das relações sociais que aparecem ao indivíduo como dadas e os efeitos da sociedade reificada sobre os indivíduos, pela via da divisão do trabalho e abstração do trabalho humano, em que a "[...] fragmentação do objeto da produção implica necessariamente a fragmentação do seu sujeito [...]" (Ibidem, p. 203).

A percepção de uma segunda natureza e de leis autônomas em relação aos homens é manifesta em Dämmerung:

O homem de negócios depende de leis que nem ele, nenhum outro homem, ou sequer um poder investido pelos homens para tal elaborou conscientemente e voluntariamente; leis das quais se servem habilmente os grandes capitalistas e talvez ele mesmo, mas cuja existência deve ser aceita como um fato. A boa ou má conjuntura, a guerra, inclusive as propriedades dos homens e das coisas exigidas na situação dada da sociedade estão condicionadas por essas leis, pela realidade social autônoma assim como está a rotação da terra condicionada pelas leis da natureza morta. [...]. O modo de pensar burguês aceita a realidade como sobrehumana. Fetichiza o processo social. (HORKHEIMER, 1986, p. 70, grifo nosso).

Neste trecho, Horkheimer se refere a uma realidade social que se autonomiza, se torna sobrehumana. Através destas referências e do verbo fetichizar, o autor faz alusão à noção de reificação. Este conceito segue presente em seus textos dos anos 1930, como ressalta Nobre (2001, p. 107-127). Pode-se considerar que é justamente o objetivo de superar a sociedade reificada, visando à emancipação, que impele a Teoria Crítica. Afinal, de modo similar ao aforismo citado, em “Teoria tradicional e Teoria Crítica", o autor aponta que os processos sociais aparecem aos homens como naturais - e inclusive utiliza novamente o termo sobrehumano:

[...] este processo [a ação conjunta dos homens na sociedade], com seus resultados, é estranho a eles próprios; parece-lhes, com todo o seu desperdício de força de trabalho e vida humana, com seus estados de guerra e toda a miséria absurda, uma força imutável da natureza, um destino sobrehumano. (HORKHEIMER, 1980, p. 136, grifo nosso).

O interesse de Horkheimer na análise dos desdobramentos concretos da reificação o impele além do pensamento de Marx, como observa Abromeit:

Mesmo considerando que Marx certamente não poderia ser acusado de falhar em prover evidência empírica para sua tese mais geral, Horkheimer se move um passo além dele, no sentido específico de que descreve em detalhes mais sutis as manifestações sociais e psicológicas no indivíduo concreto das "leis" que governam o capitalismo monopolista. (ABROMEIT, 2011, p. 159).

Especialmente com relação à análise da ideologia, Horkheimer traz uma nova contribuição. Por um lado, assim como na análise marxiana, a ideologia não é tratada apenas como questão de conviç̧ão subjetiva, uma manipulação que basta desmascarar, mas, de modo mais complexo, como enraizada na estrutura objetiva da sociedade, necessária. Porém, Horkheimer dá um passo além da análise marxista tradicional, ao se voltar ao estudo dos indivíduos concretos que reproduzem ideologias, "[...] ilustrando como estes mecanismos operam sobretudo em um nível extremamente sutil, até mesmo inconsciente [...]", como nota Abromeit (Ibidem, p. 164). 
Em uma primeira análise, esta poderia parecer uma opção compartilhada com Lukács, na medida em que este se ocupa do estudo da consciência reificada do burguês e do proletário:

[...] a estrutura da reificação, no curso do desenvolvimento capitalista, penetra na consciência dos homens de maneira cada vez mais profunda, fatal e definitiva. (LUKÁCS, 2012, p. 194).

Porém, em seus aforismos, Horkheimer se volta ao estudo dos indivíduos concretos, ao trazer diversos exemplos voltados ao particular, à esfera íntima e de atitudes cotidianas. Justamente este interesse leva o autor a se voltar ao estudo da psicanálise, disciplina que seria importante para as pesquisas do Instituto nos anos 1930, em um conjunto com Erich Fromm.

Há outros pontos de aproximação, mas também de afastamento de Horkheimer em relação a Lukács. De modo similar, ambos consideram que os efeitos da reificação têm efeitos sobre todas as posições sociais. Vale asseverar também que, assim como Lukács, que não desconsidera a diferente situação de proletários e burgueses na sociedade reificada, Horkheimer reconhece que as posições do proletário, do não possuidor de bens e do miserável são mais vulneráveis. No entanto, há uma distinção importante: Lukács vislumbra uma saída da reificação, seja através da identidade sujeito-objeto propiciada pelo proletariado ou da atuação do partido, enquanto Horkheimer, embora se ocupe em diversos aforismos das possibilidades revolucionárias, não compartilha desta confiança. A razão dessa divergência pode estar na complexidade da realidade social percebida pelo autor na Alemanha de fins dos anos 1920 e início dos anos 1930, com a existência de uma divisão dentro do proletariado e a consequente dificuldade de sua organização (HORKHEIMER, 1986, p. 85).

Alguns exemplos devem servir para ilustrar essas considerações. Nestes aforismos, é apresentada uma análise dos efeitos da configuração social sobre a autonomia dos indivíduos. Pois, face à necessidade de segurança, o possuidor de bens se coloca em uma posição de defesa de suas posses, tornando-se dependente, previsível: "[...] deixam, portanto, de ser pessoas, para ser funções do capital e seus bens [...]" (Ibidem, p. 61). Já os assalariados, por medo de sanções, renunciam a decisões próprias e a seu livre pensar. A própria forma de organização das relações sociais faria com que os indivíduos sempre se defrontassem com o risco de perder sua posição. Em outro aforismo, o valor do homem é comparado ao de uma mercadoria, pois atribuído socialmente: ao valor de uso da mercadoria corresponde o êxito social obtido, seja por nascimento ou habilidade (Ibidem, p. 97). Também, tendo em vista a influência do social sobre a esfera íntima, são expostos os condicionantes relativos à posição social que atuam sobre as reações psíquicas e a formação do caráter (Ibidem, p. 11).

Além disso, são analisadas as atitudes adaptativas dos indivíduos, consideradas em termos de utilidade para a manutenção da ordem vigente. No aforismo "Maus superiores", é evidenciada a conveniência da aparência de uma boa relação entre as diferentes classes sociais:

[...] todas estas relações devem comportar a marca da simpatia e da evidência. Se homens de diferentes classes se falam e se dão a mão, se deve ter a vívida impressão de que tudo está como deveria. (Ibidem, p. 119).

O autor também considera que tais atitudes adaptativas são interiorizadas: “[...] sua consciência se adapta a seus atos. Porque as pessoas gostam de agir de acordo com suas crenças normalmente acabam acreditando naquilo segundo o qual querem atuar." (Ibidem, p. 46). Esta interiorização dos condicionantes sociais parece decorrer do já mencionado medo da perda de posição social, mas também das vantagens que tal cooperação pode trazer (Ibidem, p. 41, 92).

O tema da moral é também relacionado ao contexto social e recebe um tratamento materialista. O aforismo "Caráter e ascensão social" (Ibidem, p. 25) aponta o 
condicionamento econômico da possibilidade do agir moralmente, ao afirmar que um milionário tem maior margem para ter qualidades ditas admiráveis e favorecer seus trabalhadores do que um pequeno fabricante, que não pode abrir mão de atitudes exploratórias para sobreviver. Ademais, no aforismo "A liberdade da escolha moral", (Ibidem, p. 125) o autor sugere que a concepção burguesa de moral exclui os miseráveis, por duas razões: a identificação com o sofrimento não lhes diz respeito, pois estes já estão entre os que sofrem, e a renúncia tampouco se aplica a eles, pois nada têm a renunciar. Já o atributo moral da gratidão é percebido como um meio utilizado contra os que se opõem à ordem vigente, dado que os membros da classe dominante são sempre aqueles a quem se deve gratidão, utilizando a proteção, a ajuda e a benevolência em favor da manutenção da ordem (Ibidem, p. 132). Assim, índices tradicionais da moral já não se referem a todas as camadas sociais e entre os aforismos há um tom geral de acusação com relação à tolerância às falhas morais dos membros das classes dominantes.

A respeito da flexibilidade moral da classe dominante, o autor afirma que não há infâmia que não se justifique caso seja de seu interesse (Ibidem, p. 128). Horkheimer qualifica uma alteração que teria ocorrido nas concepções morais da sociedade, com base na mudança da forma de atuação das classes dominantes. O aforismo "Mudanças na moral" critica os escritores radicais que crêem que a denúncia da realidade injusta é suficiente para sensibilizar, ignorando o fato de que a injustiça já não é um argumento eficaz:

[...] aceitam tacitamente a mentira harmônica dos decênios anteriores segundo a qual não obstante os diferentes interesses materiais uma convivência comum unifica a humanidade e portanto, em lugar de avançar na nova realidade convertem-se em petimetres de uma antiga ideologia. A moral a que apelam foi arquivada há tempos pela burguesia, que se converteu em imperialista. (Ibidem, p. 123) ${ }^{13}$

Estas considerações evidenciam o quanto Horkheimer relativiza a moral, considerando a distinta forma como ela se apresenta a cada classe social e sua relação com o momento histórico, com a forma de organização social. As questões morais não parecem relacionadas a princípios universalmente acessíveis, mas são denunciadas em sua contingência. Este procedimento seria mais bem desenvolvido em "Materialismo e moral" (1933), em que o autor confronta o imperativo categórico, oriundo da filosofia kantiana, com uma crítica materialista, que relaciona a configuração da moral com base em deveres à separação de interesses entre o todo social e os indivíduos. Essa separação se relaciona ao fato de a vantagem econômica ser o princípio dominante da vida, sendo os indivíduos impelidos a atuar em busca de sua proteção através do acúmulo de propriedades (HORKHEIMER, 2011c, p. 61-63). Horkheimer considera a moral como fruto de uma ordem social que pode ser superada, algo que Kant não teria percebido por eternizar as categorias da sociedade burguesa, assim como teriam feito outros filósofos considerados tipicamente burgueses, como Hegel e Nietzsche. E, sendo a moral fruto desta configuração social, uma vez superadas as contradições do capitalismo em uma nova ordem social racionalmente planejada, a concepção corrente de moral tenderia a desaparecer.

Porém alguns aspectos envolvidos na questão moral não são descartados por Horkheimer. Um deles é a compaixão (Idem, 1986, p. 20, 22, 41, 49, 50, 115, 120, 121, 127, 128). É comum, na literatura de comentário, sua associação à influência sobre

\footnotetext{
${ }^{13}$ Tendo em vista o desenvolvimento posterior da obra de Horkheimer, vale comentar como tal mudança deriva de alterações econômicas, ou seja, da passagem do capitalismo liberal ao capitalismo monopolista. Nessa transição, há acumulação de capital em poder de poucos grupos, perdendo importância o modelo de empreendedor liberal. Um exemplo do peso dessa mudança nos atributos psíquicos dos indivíduos pode ser encontrado em “Observações sobre antropologia filosófica” (1935) (HORKHEIMER, 1993, p. 173-174).
} 
Horkheimer da leitura de Schopenhauer ${ }^{14}$. Como atestado pelo próprio Horkheimer, Schopenhauer representou seu primeiro contato com a filosofia e permaneceu em seu arcabouço teórico, pois, conforme escreve em 1968, “[...] a sociedade melhor, a sociedade justa, é uma meta que se mistura com a ideia de culpa [...]" (Idem, 2011d, p. 4). Entre os aforismos, esta noção já se fazia presente pelo espaço reservado ao tema do sofrimento de homens e animais. Horkheimer vai além, ao considerar que tais sofrimentos seriam desnecessários, pois a humanidade já teria alcançado condições técnicas para sua eliminação (Idem, 1986, p. 41). Ademais, poderiam servir de incentivo para perseverar na busca pelo socialismo, mesmo com todas as incertezas implicadas (Idem, 1986, p. 50). Assim, na filosofia de Horkheimer, este impulso encontrado no reconhecimento do sofrimento de outrem se une ao marxismo, atuando como motor da busca por uma sociedade melhor.

De acordo com alguns intérpretes, entre eles Alfred Schmidt (SCHMIDT, 1993, p. 28-31; WIGGERSHAUS, 2002, p. 83, 84), pode ser caracterizada certa aliança entre as ideias de Marx e Schopenhauer, na recusa de Horkheimer à transfiguração do sofrimento humano. Essa associação da compaixão com aspirações marxistas só é possível por duas razões. Em primeiro lugar, de acordo com Abromeit, pois Horkheimer não hipostasia "a negatividade do mundo, garantindo-lhe o status de um princípio metafísico", não opta pela "fuga do mundo, ou a vê-lo simplesmente em termos de desprezo" (ABROMEIT, 2011, p. 47), como faria Schopenhauer. Além disso, como ressalta Schmidt (SCHMIDT, 2011, p. 32, 1986, p. 193), para Horkheimer o sofrimento não é transfigurado em um projeto metafísico de redenção, pois sua concepção de história é contrária à ideia de um fim superior na marcha dos eventos históricos.

Vale apontar que, para o autor, embora em uma nova configuração social organizada de modo racional, a moral como é conhecida tenderia a desaparecer (por ser baseada justamente na separação dos interesses individuais e do todo), a compaixão poderia ainda sobreviver, dado que nem todas as formas de sofrimento humano são oriundas desta forma de organização social.

A leitura dos aforismos também permite atestar que Horkheimer não abre mão dos ideais iluministas. Estes ideais são relacionados pelo autor a um potencial revolucionário da burguesia nascente, que já fora diagnosticado pelo próprio Marx. No aforismo "A luta contra o burguês" (HORKHEIMER, 1986, p. 194), é feita uma advertência contra a crítica aos ideais burgueses, pois tenderia a negar também os aspectos revolucionários desse pensamento. Tal crítica seria apenas de interesse do grande capital, tendo a burguesia nesse momento já deixado de ser o grupo dominante economicamente ${ }^{15}$. Em "Modos de sepultar" (Ibidem, p. 34), são enumeradas as formas pelas quais teorias podem ser neutralizadas. O autor cita Voltaire, Rousseau, Lessing, Kant, considerando que, embora a sociedade faça reverência a eles como grandes homens,

seus sentimentos, os motivos e impulsos que os animaram, o sentido de suas doutrinas, seu caráter irreconciliável com a injustiça reinante são rechaçados e escarnecidos, valorados como pobres e superficiais (Ibidem).

Ao comentar este aforismo, Abromeit afirma a respeito da posição de Horkheimer quanto aos ideais iluministas: "ilustra que seu potencial crítico pode ter sido desarmado, mas de forma alguma exaurido" (ABROMEIT, 2011, p. 171). Também, posteriormente, no ensaio "Materialismo e moral", Horkheimer afirmaria que, embora os ideais do

\footnotetext{
${ }^{14}$ Diversos intérpretes associam as filosofias de Horkheimer e Schopenhauer quanto ao tema da compaixão, que também é mencionado em "Materialismo e moral" e, de modo distinto, em Dialética do esclarecimento (ABROMEIT p. 160; SCHMIDT, 1993, p. 28-31; STIRK, 2000, p.165).

${ }^{15}$ Observe-se que também esta afirmação está no contexto da passagem do capitalismo liberal para o capitalismo monopolista.
} 
Iluminismo e da Revolução Francesa não encontrem realização no presente, o anseio que eles carregam é legítimo. O autor considera que a meta da política deveria ser concretizar tais ideais, e que justamente o fato de estarem não realizados, de não terem perdido assim sua atualidade, encorajaria a crítica dialética do mundo. Ao aludir a ideais como justiça, igualdade e liberdade em termos de seu potencial e sua não efetivação, reforça que, mesmo assim, tais exigências não devem ser abandonadas. Nesse sentido, afirma que

[...] estas ideias não são senão as características individuais da sociedade racional, tal qual ela é antecipada na moral como meta necessária (...) [e] uma política correspondente não deve abandonar estas exigências, mas realizá-las. (HORKHEIMER, p. 79, 2011b).

\section{Considerações finais}

O interesse pelas consequências da vida na sociedade reificada sobre indivíduos concretos é mencionada por Abromeit (ABROMEIT, 2011, p. 158) como algo que levaria Horkheimer à aproximação com outras disciplinas, como a psicanálise, inserida na linha de pesquisas do Instituto nos anos 1930. Isso nos remete ao papel da ciência na sociedade de então, pois a crítica à pretensa neutralidade da ciência, confrontada com seu efetivo conformismo em relação à ordem vigente, é essencial na formulação da Teoria Crítica. Horkheimer e o seu grupo de trabalho buscam, através da cooperação com outras disciplinas e da formulação da Teoria Crítica, uma saída para a unilateralidade da ciência. Embora Lukács tenha influenciado Horkheimer em diversos aspectos, este é um ponto de divergência, pois, como ressalta Nobre (NOBRE, 2001, p. 114-115), Lukács não considerava esta possibilidade, por permanecer relacionando a especialização das ciências com a eliminação de seu potencial crítico.

Horkheimer e outros integrantes do Instituto se afastam da ortodoxia marxista ao incluir a psicanálise em seu programa de pesquisas, uma vez que esta disciplina era tradicionalmente desprezada pelos teóricos do marxismo ocidental. Jay (1984, p. 204) comenta, a respeito dos objetivos desta disciplina no Instituto: "embora a economia ainda fosse o motor primário do comportamento humano, as mediações psicológicas entre a infra-estrutura e as ações e crenças de homens reais deveriam também ser investigadas". Em "História e psicologia" (1932), Horkheimer (2011a) justifica o interesse da psicologia para seu programa de pesquisas:

Na raiz deste momento histórico particularmente importante (...) [está] a estrutura psíquica total destes grupos, isto é, o caráter de seus membros se renova constantemente em relação com o seu papel no processo econômico. Por isso, a psicologia avançará até estes fatores psíquicos mais profundos, por meio dos quais a economia determina o homem; ela será mormente psicologia do inconsciente.

De acordo com Jay, com este interesse na psicologia individual, o autor seria leal a uma das mais importantes premissas de seu pensamento:

[...] a irredutibilidade do individual ao coletivo. Embora reconhecendo o fim inevitável da era liberal, [Horkheimer] reteve seu conceito individualista de homem. (JAY, 1984, p. 211).

Isso não significava, entretanto, corroborar um individualismo cego, mas ter como impulso crítico a busca pela felicidade individual. Há uma relação desta postura com o momento histórico de ascensão dos autoritarismos, pois "na presente era de crescente autoritarismo o balanço estava pendendo na direção de coletividades opressivas" (Ibidem). Essa preocupação está expressa nas afirmações de Horkheimer contra o sacrifício e a ideia de nação (HORKHEIMER, 1986, p. 34).

Com a leitura destes aforismos, é evidenciado como a noção de reificação permeia a filosofia de Horkheimer desde os anos 1920, envolvendo sobretudo uma análise voltada 
ao indivíduo concreto, interesse que se concatena com as diretrizes metodológicas do Instituto nos anos 1930. Ademais, neles já há indícios importantes da recepção de Lukács por Horkheimer, em sua complexidade, para além do conceito de reificação.

Correspondência: Simone Bernardete Fernandes. Universidade de São Paulo - USP, Av. Prof. Luciano Gualberto, 315, sala 1007, CEP 05508-010, São Paulo, SP, Brasil. E-mail: simonebfernandes@uol.com.br Conflito de interesses: Nenhum.

Todos os autores leram e aprovam a versão final submetida a revista Em curso. 


\section{Bibliografia}

ABROMEIT, J. Max Horkheimer and the foundations of the Frankfurt School. New York: Cambridge University Press, 2011.

ADORNO, T.; HORKHEIMER, M. (2006). Dialética do esclarecimento: fragmentos filosóficos. Tradução de Guido Antonio de Almeida. Rio de Janeiro: Zahar.

BRUNKHORST, H. “Dialectical positivism of happiness: Horkheimer's materialist deconstruction of philosophy" In: BENHABIB, S.; BONB, W.; MCCOLE, J. (Org.). On Max Horkheimer: new perspectives. Cambridge, Massachusetts, London: The MIT Press, 1993.

HABERMAS, J. Observações sobre o desenvolvimento da obra de Max Horkheimer. Revista Educação e Filosofia, v. 21, n. 42, p. 273-293, 2007.

HORKHEIMER, M. História e psicologia. In: Teoria Crítica: uma documentação. Tradução de Hilde Cohn. São Paulo: Perspectiva, 2011a.

HORKHEIMER, M. Materialismo e metafísica. In: Teoria Crítica: uma documentação. Tradução de Hilde Cohn. São Paulo: Perspectiva, 2011b.

HORKHEIMER, M. Materialismo e moral. In: Hilde Cohn. São Paulo: Perspectiva, 2011c.

HORKHEIMER, M. Prefácio para a reedição. In: Hilde Cohn. São Paulo: Perspectiva, 2011d.

HORKHEIMER, M. Da discussão do racionalismo na filosofia contemporânea. In: Teoria Crítica: uma documentação. Tradução de Hilde Cohn. São Paulo: Perspectiva, 2011e.

HORKHEIMER, M. Los comienzos de la filosofía burguesa de la historia. Traducción de Maria del Rosario Zurro. In: Historia, metafísica y escepticismo. Madrid: Alianza Ed., 1982a.

HORKHEIMER, M. Hegel y el problema de la metafísica. Traducción de Maria del Rosario Zurro. In: . Historia, metafísica y escepticismo. Madrid: Alianza Ed., 1982b.

HORKHEIMER, M. Ocaso. Traducción de José Ortega. Barcelona: Ed. Anthropos, 1986.

HORKHEIMER, M. Remarks on philosophical anthropology. Tradução de G. Frederick Hunter, Matthew S.Kramer and John Torpey. In: Between philosophy and social science: selected early writings studies in contemporary german social thought. Massachusetts: MIT Press, 1993.

HORKHEIMER, M. Sobre a metafísica do tempo de Bergson. Cadernos de Filosofia Alemã: Crítica e Modernidade, n. 6, p. 61-83, 2000. http://dx.doi.org/10.11606/issn.2318-9800.v0i6p61-83.

HORKHEIMER, M. Teoria tradicional e Teoria Crítica. Tradução de Edgard Afonso Malagodi e Ronaldo Pereira Cunha. In: __. Benjamin, Walter; Horkheimer, Max; Habermas, Jürgen; Adorno, Theodor. Textos escolhidos. São Paulo: Abril Cultural, 1980.

HORKHEIMER, M. A presente situação da filosofia social e as tarefas de um instituto de pesquisas sociais. Praga, Estudos Marxistas, n. 7, p. 121-132, mar. 1999.

JAY, M. A Imaginação Dialética: história da Escola de Frankfurt e do Instituto de Pesquisas Sociais, 1923-1950. Rio de Janeiro: Contraponto, 2008.

JAY, M. Max Horkheimer and the retreat from Hegelian Marxism. In: Marxism and totality: the adventures of a concept from Lukács to Habermas. Berkeley: University of California Press, 1984.

LUKÁCS, G. História e consciência de classe. Tradução de Rodnei Nascimento. São Paulo: Martins Fontes, 2012.

MARX, K. O Capital. Tradução de Régis Barbosa e Flávio R. Kothe. São Paulo: Abril Cultural, 1985. v. 1. NOBRE, M. Curso Livre de Teoria Crítica. Campinas: Papirus, 2008.

NOBRE, M. Lukács e os limites da reificação: um estudo sobre História e Consciência de Classe. São Paulo: Editora 34, 2001.

NOBRE, M. Max Horkheimer: a teoria crítica entre o nazismo e o capitalismo tardio. In: . Curso Livre de Teoria Crítica. Campinas: Papirus, 2008.

SCHMIDT, A. "Max Horkheimer's intellectual physiognomy". In: BENHABIB, S.; BONB, W.; MCCOLE, J. (Org.). On Max Horkheimer: new perspectives. Cambridge, Massachusetts, London: The MIT Press, 1993.

SCHMIDT, A. L'oeuvre de jeunesse de Horkheimer et la naissance de la théorie critique. Archives de Philosophie, 1986, v. 49, p. 79-204. 
STIRK, P. Critical theory, politics and society: an introduction. London: Continuum, 2000.

STIRK, P. Max Horkheimer: a new interpretation. Hemel Hempstead, Harvester Wheatsheaf, 1992.

STIRK, P. Philosophy in an authoritarian age. In: Max Horkheimer: a new interpretation. Hemel Hempstead: Harvester Wheatsheaf, 1992. p. 37-61.

WIGGERSHAUS, R. A Escola de Frankfurt: história, desenvolvimento teórico, significação política. Tradução de Lilyane Deroche-Gurcel e Vera de Azambuja Harvey. Rio de Janeiro: Difel, 2002. 